\title{
Smoking cessation interventions in COPD: a network meta-analysis of randomised trials
}

\author{
R. Strassmann*, B. Bausch*, A. Spaar*, J. Kleijnen ${ }^{\#, ๘}$, O. Braendli ${ }^{+}$and M.A. Puhan* ${ }^{\S}$
}

ABSTRACT: The aim of this study was to rank order the effectiveness of smoking cessation interventions for chronic obstructive pulmonary disease (COPD) patients.

We searched 10 databases to identify randomised trials of smoking cessation counselling (SCC) with or without pharmacotherapy or nicotine replacement therapy (NRT). We conducted a network meta-analysis using logistic regression analyses to assess the comparative effectiveness of smoking cessation interventions while preserving randomisation of each trial.

The analysis of 7,372 COPD patients from six out of eight identified trials showed that SCC in combination with NRT had the greatest effect on prolonged abstinence rates versus usual care (OR 5.08, $\mathrm{p}<0.0001)$ versus SCC alone $(2.80, \mathrm{p}=0.001)$ and versus SCC combined with an antidepressant $(1.53, p=0.28)$. The second most effective intervention was SCC combined with an antidepressant $(3.32, p=0.002)$ versus SCC alone $(1.83, p=0.007)$, with no difference between antidepressants. SCC alone was of borderline superiority compared with usual care (1.81, $p=0.07$ ).

A small body of evidence suggests that SCC combined with NRT is more effective than other combinations and single smoking cessation treatments in COPD, but substantially more research is needed for this most important COPD treatment.

KEYWORDS: Chronic obstructive pulmonary disease, mortality, network meta-analysis, prolonged abstinence rates, randomised trials, smoking cessation

moking cessation is the single most important intervention to prevent chronic obstructive pulmonary disease (COPD) or to reduce its progression [1]. It slows down the progression of lung function decline, improves symptoms and may reduce exacerbations [2-5]. The Lung Health Study recently showed impressive long-term results with a reduction of all-cause mortality in patients randomised to a smoking cessation intervention 14.5 yrs earlier [6].

Although it is extremely important, relatively little was known about smoking cessation interventions in COPD until recently. In a previous systematic review no firm evidence was found with respect to the relative effectiveness of different smoking cessation interventions [7]. Relative effectiveness, also called comparative effectiveness, refers to the effectiveness of a treatment strategy (e.g. antidepressants for smoking cessation) relative to the effectiveness of another treatment strategy, for example nicotine replacement therapy (NRT). However, there is a large body of evidence regarding the effects of smoking cessation interventions in smokers. From the literature, we know that simple smoking cessation advice given by the general practitioner or the provision of self-help material (generally referred to as smoking induction interventions) only marginally, although statistically significantly, enhances smoking cessation rates [8, 9]. More time consuming and structured individual or group smoking cessation counselling (SCC) appears to be more effective [10, 11]. However, evidence does not suggest that more intensive SCC is clearly superior to low intensity counselling $[10,11]$. A large number of trials found additional benefit if NRT was added to SCC [12]. Finally, some but not all antidepressants enhance smoking cessation rates compared to SCC alone [13].

It is still unclear whether this evidence is applicable to COPD patients because their motivation to stop smoking might differ [14-16]. Also, there are few direct randomised comparisons of competing smoking cessation regimens. With few direct comparisons and the unlikelihood of a single large trial comparing all commonly available regimens, a network metaanalysis can be very informative [17]. Network metaanalyses unify evidence from all randomised trials while fully preserving randomisation [18-20]. Therefore, our aim was to conduct a network metaanalysis in order to rank order the effectiveness of smoking cessation interventions for COPD patients.

\section{AFFILIATIONS}

*Horten Centre for patient-oriented research and knowledge transfer University of Zurich, and ${ }^{+}$Division of Pneumology, University Hospital of Zurich, Zurich, Switzerland.

\#Kleijnen Systematic Reviews Ltd, York, UK.

'School for Public Health and Primary Care, CAPHRI, University of Maastricht, Maastricht, The Netherlands.

${ }^{\S}$ Dept of Epidemiology, Johns Hopkins Bloomberg School of Public Health, Baltimore, MD, USA.

\section{CORRESPONDENCE}

M.A. Puhan

Dept of Epidemiology

Johns Hopkins Bloomberg School of Public Health

615 N. Wolfe St

21205 Baltimore

$M D$

USA

E-mail: mpuhan@jhsph.edu

Received:

Nov 052008

Accepted after revision:

March 312009

First published online:

April 082009 


\section{METHODS}

\section{Selection criteria}

We included randomised controlled trials of smoking cessation interventions in COPD patients if they had spirometrically confirmed COPD and/or if they had physician-diagnosed COPD. We excluded studies with smokers without evidence of COPD.

We considered any nonpharmacological and pharmacological intervention which assisted patients in preparing a quit smoking attempt and supported patients during smoking abstinence. Behavioural interventions were classified as individual or group setting, self-help material and telephone counselling. We considered any pharmacological interventions with NRT, antidepressants or other drugs.

\section{Search strategy}

This systematic review was part of a large review project on various treatments for COPD. Therefore, we used a very broad strategy to search for relevant studies in the following databases from their setup through to October 2006: Medline, Embase, Latin American and Caribbean Health Sciences Literature, Cochrane Database of Systematic Reviews, Cochrane Central Register of Controlled Trials, Database of Abstracts of Reviews of Effects, Health Technology Assessment database, Cinahl, Biosis and the National Research Register. We used the key words "COPD", "pulmonary disease, chronic obstructive", "emphysema", "treatment outcome" and "randomised controlled trial". We checked references of retrieved articles and entered all included studies into the related articles function of PubMed. The last search for studies published after October 2006 was performed on November 4, 2008. Finally, we used existing systematic reviews to identify further articles. The full search strategy including its keywords is available from the authors.

\section{Study selection}

All identified citations were independently assessed by two members of the review team (R. Strassmann, B. Bausch, A. Spaar and M.A. Puhan) without imposing any language restrictions. The full text of the citations, for which at least one of the reviewers concluded that they seemed potentially eligible, was then independently evaluated by two reviewers who decided on in- and exclusion, paying close attention to the eligibility criteria. If there was no agreement about in- and exclusions after discussion among the two reviewers, a third reviewer was called upon to make the desicion.

\section{Data extraction and quality assessment}

One reviewer recorded details about study design, interventions, patients, outcome measures and results in predefined Microsoft Windows ACCESS forms and a second reviewer checked data extraction for correctness. Smoking cessation interventions vary greatly and may range from provision of self-help material without person-to-person contact to extensive individual or group counselling with or without additional NRT or pharmacotherapy. As in previous reviews $[7,10$ 12], we categorised SCC into interventions of low or high intensity as reporting interventions generally does not allow for a detailed categorisation. We considered SCC to be of low intensity if: the authors labelled it as such; the duration of single SCC sessions was short $(\leqslant 10 \mathrm{~min})$; or the number of sessions was less than or equal to five. We categorised interventions as high-intensity SCC if: the authors labelled it as such; and SCC sessions were longer (>10 $\mathrm{min}$ ) and more frequent (more than five times).

For each trial, two reviewers independently evaluated the quality of reporting for important components of internal validity. We assessed if the generation of the randomisation sequence was adequate, how concealment of random allocation was achieved, whether eligibility criteria were specified, if the groups appeared comparable at baseline, whether outcome assessors, treatment providers and patients were blinded to treatment (where possible) and if an intention-to-treat analysis was performed. We resolved discordant scores based on real differences in interpretation through consensus or third party arbitration. We used quality assessment to judge the validity of the trial results but did not exclude trials of low methodological quality from the analyses.

\section{Outcome measures}

The primary outcome measure was prolonged abstinence rate after $\geqslant 6$ months with biochemical confirmation, such as exhaled carbon monoxide, cotinine levels or carboxyhaemoglobin. For each trial arm (two to four depending on the trial), we registered the number of patients with prolonged abstinence and the number of patients without prolonged abstinence $(2 \times 2,3 \times 2$ or $4 \times 2$ tables). If prolonged abstinence rates were not available we also considered point-prevalence abstinence rates. Point-prevalence abstinence rate refers to the proportion of patients who have not smoked at a specific point of time during follow-up (usually 7 days prior to a follow-up assessment). It is a considerably less valid estimate of smoking abstinence than the prolonged abstinence rate, because patients could be classified as nonsmokers even if they had smoked a week before the reference date. In addition, we extracted data about long-term outcomes such as mortality if available.

\section{Statistical analysis}

We conducted a network meta-analysis, which is an extension of conventional meta-analysis offering several advantages. Network meta-analysis also compares effect estimates across randomised trials but includes direct and indirect comparisons. For example, treatments A and B have both been compared to placebo but not to one another. If randomisation is kept intact (A versus placebo and B versus placebo) a valid indirect comparison of A versus B is possible. Network meta-analysis allows not only the comparison of two treatments where few or no direct comparisons exist but a simultaneous comparison of several competing treatment strategies. Thus, treatments can be rank-ordered according to their relative effectiveness. In addition, assessment of effect modification is more realistic because it is based on a much larger body of evidence than in conventional metaanalysis [21].

We conducted a network meta-analysis using a fixed effect and a random coefficient-logistic regression model as described earlier [21]. To prepare the dataset for these analyses we reconstructed the original data sets with patient-level data based on $2 \times 2$ tables from each study (or $3 \times 2$ and $4 \times 2$ tables, respectively). For each cell of these tables we created the 
corresponding number of individual patients in the final dataset. Thus, the data set was identical to that of the original trials but without specifying individual patient profiles (age, sex, etc.). We performed a fixed effect logistic regression analysis on these patient-level data with prolonged abstinence as the dependent variable and the different treatment options as the independent variable. Thereby, we compared all smoking cessation treatments with each other. To preserve randomisation within each trial, we included a dummy variable for each of the studies. This dummy variable also adjusted for differences in patient profiles and study setup between trials. With a random coefficient model, we investigated the presence of any additional variation of the treatment effects due to differences across trials. All analyses were conducted using STATA (version 9.2; StataCorp, College Station, TX, USA).

\section{RESULTS}

\section{Identification of studies}

Figure 1 summarises the process of identifying eligible randomised trials. We initially selected 1,143 studies for full text assessment, of which 24 were about smoking cessation interventions. We excluded 11 of these studies because they were not randomised and another five studies because they did not focus on COPD patients. We finally included eight trials with a total of 7,477 COPD patients [22-29].

\section{Study characteristics}

Table 1 shows details about the populations, interventions, outcomes and prolonged abstinence rates from the included trials. Three trials included patients with mild-to-moderate airflow obstruction [22, 27, 29], two trials included patients with moderate-to-severe airflow obstruction [24, 28], whereas three other studies did not provide data on airflow obstruction $[23,25,26]$. Six trials had two or more treatment groups providing various comparisons between usual care or minimal smoking cessation advice, SCC alone, or SCC in combination with NRT or an antidepressant. Four studies [22, 26-28] used interventions of high intensity in an individual and/or group setting. Five studies [23-25, 28, 29] offered interventions of low intensity. One trial [23] assessed the effect of different labelling of COPD during SCC (smokers lung versus chronic bronchitis) and another trial [24] assessed the effects of rewarding patients for smoking abstinence. In six trials [22, 25-29], prolonged abstinence rates after 6 or 12 months or even 5 yrs was the main outcome, whereas five trials reported on pointprevalence abstinence rates after 6 or 12 months [23-25, 28, 29]. A previous trial has reported on mortality 14.5 yrs after randomisation [6].

\section{Quality of the trials}

Blinding was more often reported than the method of randomisation or concealment of random allocation (table 2). Overall, three trials appeared to be of good quality $[6,27,29]$, two of moderate quality [25, 28] and three of low quality $[23,24,26]$.

\section{Effects on prolonged abstinence rates}

SCC in combination with NRT yielded the greatest effect on prolonged abstinence rates (table 3 ). The odds of prolonged abstinence were five times higher compared with no intervention or usual care (OR 5.08, 95\% CI 4.32-5.97), three times higher compared with SCC alone (OR 2.80, 95\% CI 1.49-5.26), and (nonsignificantly) 1.5 times higher compared with SCC in combination with an antidepressant (OR 1.53, $95 \%$ CI 0.71-3.30). The second most effective intervention was SCC combined with an antidepressant versus usual care (OR $3.32,95 \%$ CI 1.53-7.21) and versus SCC alone (OR 1.83, 95\% CI 1.18-2.83), with no difference between the antidepressants bupropion and nortriptyline. SCC alone was of borderline superiority compared with usual care (OR 1.82, 95\% CI 0.96-3.44).

A more detailed analysis considering the intensity of SCC (table 4) showed that the odds of prolonged abstinence tended to be increased by high-intensity SCC compared with lowintensity SCC. But the odds ratios were not significant for the comparisons of high-intensity SCC alone versus low-intensity SCC (OR 1.46, 95\% CI 0.44-4.90; p=0.54) and high-intensity SCC in combination with an antidepressant versus lowintensity SCC in combination with an antidepressant (OR $1.55,95 \%$ CI 0.35-6.91; $\mathrm{p}=0.56$ ). Only high-intensity SCC plus NRT was significantly more effective than low-intensity SCC plus NRT (OR 1.81, 95\% CI 1.04-3.15; p=0.04).

\section{Effects on mortality}

Trial 2, the study by ANTHONISEN et al. [22], provided a longterm follow-up of a previous trial that reported mortality after 14.5 yrs [6], which showed that mortality was significantly reduced in the intervention groups (OR 0.74, 95\% CI 0.63-0.87). Trial 8, the study by TONNESEN et al. [28], also reported mortality after $1 \mathrm{yr} ; 3.2 \%$ of patients with NRT and $4.5 \%$ of patients with placebo had died (OR 0.74, 95\% CI 0.22-2.41).

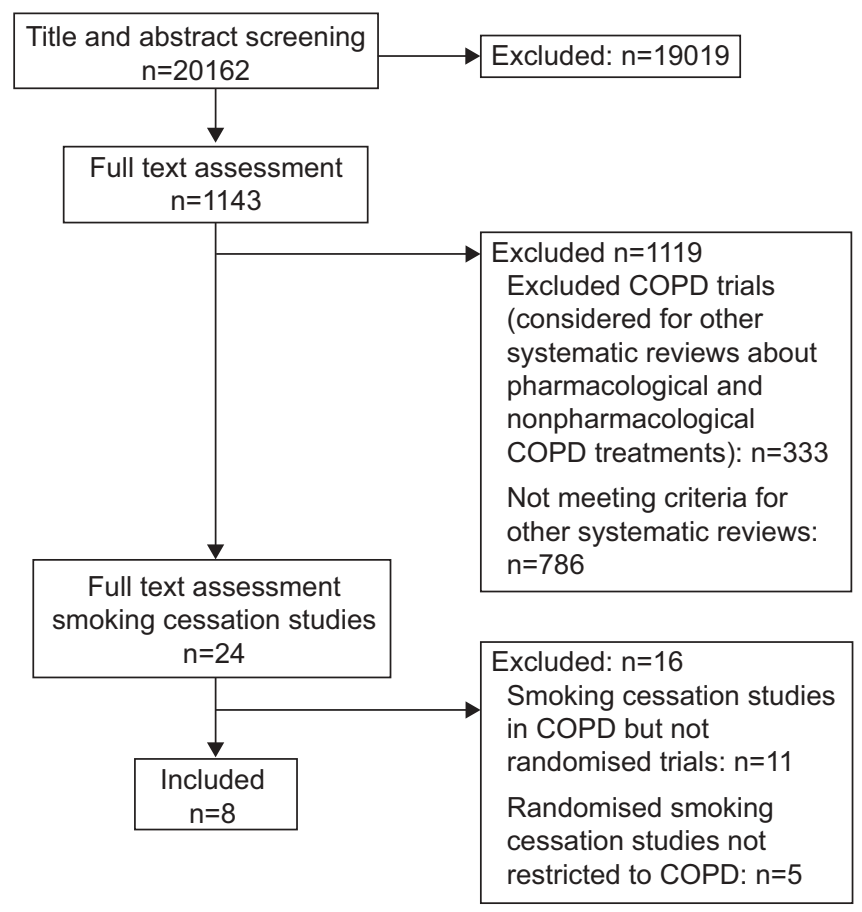

FIGURE 1. Flow chart from identification of studies to final inclusion. COPD chronic obstructive pulmonary disease. 
TABLE 1 Characteristics of included trials

\begin{tabular}{|c|c|c|c|c|}
\hline First author [ref.] & Population & Interventions & Outcomes & Smoking-cessation rates \\
\hline ANTHONISEN [22] & $\begin{array}{l}5887 \text { patients from general population } \\
\text { recruited with advertisements, at work } \\
\text { or public sites with spirometrically } \\
\text { confirmed COPD: } \\
62.9 \% \text { male; mean age } 48.5 \text { yrs, } \\
\text { mean FEV1 } 78.3 \% \text { pred }\end{array}$ & $\begin{array}{l}\text { Group 1: SCC with NRT and ipratropium bromide } \\
\text { (t.i.l.) or placebo } \\
\text { One individual SCC and } 12 \text { 2-h group sessions } \\
\text { over } 10 \text { weeks } \\
\text { Group 2: usual care (no SCC) }\end{array}$ & $\begin{array}{c}\text { Prolonged abstinence rates } \\
\text { (12 and } 60 \text { months, validated by } \\
\text { expired CO and salivary cotinine levels) } \\
\text { Mortality ( } 14.5 \text { yrs) }\end{array}$ & $\begin{array}{l}12 \text { months: } \\
\text { Group 1: } 34.5 \% \\
\text { Group 2: } 9.0 \% \\
60 \text { months: } \\
\text { Group 1: } 21.3 \% \\
\text { Group 2: } 5.2 \%\end{array}$ \\
\hline CrowLEY [24] & $\begin{array}{l}49 \text { patients recruited in general hospital } \\
\text { or outpatient chest clinic with } \\
\text { spirometrically confirmed COPD: } \\
75.7 \% \text { male; mean age } 61.4 \text { yrs, } \\
\text { mean FEV1 } 49.5 \% \text { pred }\end{array}$ & $\begin{array}{l}\text { Group 1: reinforcement with lottery tickets if } \\
\text { patients met criterion for abstinence (breath } \mathrm{CO}_{2} \text { ) } \\
\text { Group 2: reinforcement with lottery tickets equal to } \\
\text { pair-mates in group } 1 \text { irrespective of abstinence } \\
\text { Group 3: reinforcement with lottery tickets if } \\
\text { cigarette self-reported "none since last visit". } \\
\text { Groups 1-3: individual SCC ( } 30 \text { min) at baseline } \\
\text { (1-2 home visits) and self-help-material }\end{array}$ & $\begin{array}{l}\text { Smoking point prevalence at } 6 \text { months } \\
\text { (validated by expired } \mathrm{CO} \text { ) }\end{array}$ & $\begin{array}{l}13.9 \% \text { (not reported } \\
\text { per group, but no } \\
\text { significant differences) }\end{array}$ \\
\hline TASHKIN [27] & $\begin{array}{l}404 \text { patients recruited with radio and } \\
\text { print advertisements with spirometrically } \\
\text { confirmed COPD: } \\
55 \% \text { male; mean age } 53.9 \text { yrs, } \\
\text { mean FEV1 } 71.3 \% \text { pred }\end{array}$ & $\begin{array}{l}\text { Group 1: bupropion } 150 \mathrm{mg} \text { q.d. for days } 1-3, \\
150 \mathrm{mg} \text { b.i.d. for days } 4-48 \\
\text { Group 2: placebo } \\
\text { Groups } 1 \text { and 2: individual SCC at weeks } 1-7, \\
10 \text { and } 12 \text {, telephone counselling } 3 \text { days after } \\
\text { target quit date and self-help-material }\end{array}$ & $\begin{array}{l}\text { Prolonged abstinence rates } \\
\text { (6 months, validated by expired CO) } \\
\text { Smoking point prevalence at } 6 \text { months }\end{array}$ & $\begin{array}{l}\text { Group 1: } 15.7 \% \\
\text { Group 2: } 9.0 \%\end{array}$ \\
\hline WAGENA [29] & $\begin{array}{l}255 \text { patients from general practice with } \\
\text { spirometrically confirmed COPD: } \\
49.9 \% \text { male; mean age } 43.7 \mathrm{yrs}, \\
\text { mean FEV1 } 85.9 \% \text { pred }\end{array}$ & $\begin{array}{c}\text { Group 1: bupropion } 150 \mathrm{mg} \text { q.d. for days } 1-6, \\
150 \mathrm{mg} \text { b.i.d. for days } 7-84 \\
\text { Group 2: nortriptyline } 25 \mathrm{mg} \text { q.d. for days } 1-3, \\
50 \mathrm{mg} \text { q.d. for days } 3-7,75 \mathrm{mg} \text { q.d. for days } 8-84 \\
\quad \text { Group 3: placebo } \\
\text { Groups 1-3: individual SCC at baseline and } 1 \text { and } \\
3 \text { weeks after target quit date. Supportive telephone } \\
\text { calls at target quit date, and } 2,4,6,8 \text { and } 11 \text { weeks } \\
\text { after target quit date }\end{array}$ & $\begin{array}{l}\text { Prolonged abstinence rates ( } 6 \text { months, } \\
\text { validated by expired } \mathrm{CO} \text { ) }\end{array}$ & $\begin{array}{l}\text { Group 1: } 30.2 \% \\
\text { Group 2: } 28.8 \% \\
\text { Group 3: } 19.1 \%\end{array}$ \\
\hline HILBERINK [25] & $\begin{array}{l}392 \text { patients from primary care with } \\
\text { clinically diagnosed COPD: } \\
50.9 \% \text { male; mean age } 59.0 \text { yrs, } \\
\text { mean FEV } 1 \text { not stated }\end{array}$ & $\begin{array}{l}\text { Group 1: intensified "minimal intervention" with } \\
\text { patients divided into three categories: preparers, } \\
\text { contemplators, pre-contemplators. } \\
\text { Smokers unmotivated to quit received only information } \\
\text { about the advantages of quitting. Smokers motivated to } \\
\text { quit received self-efficacy enhancing visits and calls. } \\
\text { Additional } 4 \mathrm{~h} \text { of group training were offered. NRT } \\
\text { offered. } \\
\text { Group 2: usual care (no specific SCC) }\end{array}$ & $\begin{array}{c}\text { Prolonged abstinence rates } \\
\text { (6 months, validated by expired } \mathrm{CO} \text { ) }\end{array}$ & $\begin{array}{l}\text { Group 1: } 16.0 \% \\
\text { Group 2: } 8.8 \%\end{array}$ \\
\hline
\end{tabular}

COPD: chronic obstructive pulmonary disease; ACCP: American College of Chest Physicians; ATS: American Thoracic Society; FEV1: forced expiratory volume in 1 s; SCC: smoking cessation counselling; $\mathrm{COHb}$ : carboxyhaemoglobin; \% pred: \% predicted; NRT: nicotine replacement therapy.

\section{Other comparisons}

Trial 3, the study by CROWLEY et al. [24], assessed the effects of rewarding patients for smoking abstinence. Point-prevalence abstinence rates were not reported for each group separately but for all groups together $(13.9 \%)$. There were no significant differences between groups.

Trial 4, the study by BRANDT et al. [23], found a much higher (but not statistically significant) quit rate at 12 months if COPD was labelled as "smoker's lung" during SCC (point-prevalence abstinence rates $32.0 \%$ ) compared to a "chronic bronchitis" labelling (16.1\%; OR 2.71, 95\% CI 0.62-12.35). Four patients in the smoker's lung group $(16.0 \%)$ and three patients in the chronic bronchitis group $(9.7 \%)$ died during the 1-yr follow-up (OR 1.88, 95\% CI 0.30-12.55).

\section{DISCUSSION}

This network meta-analysis of a limited number of randomised comparisons of moderate to good methodological quality 


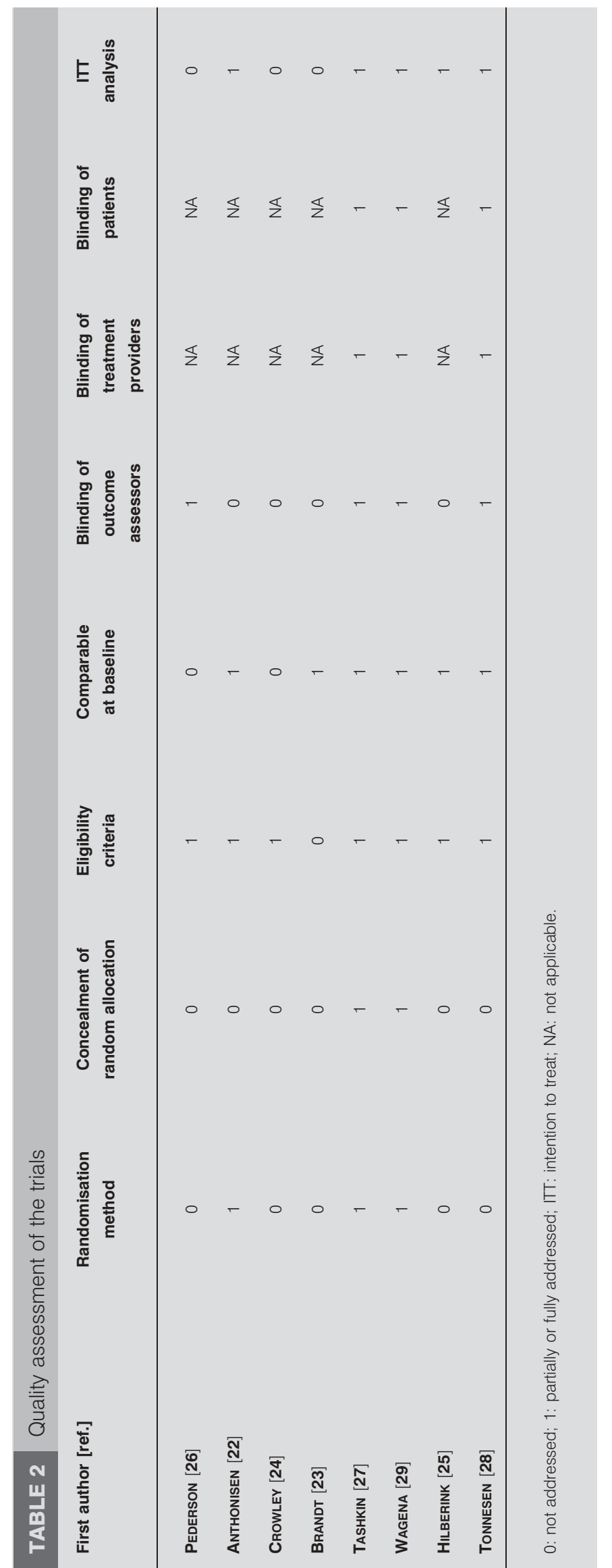

showed that SCC in combination with NRT appears to be the most effective smoking cessation intervention to enhance prolonged abstinence rates followed by SCC in combination with an antidepressant. SCC without additional drug treatment is significantly less effective and only slightly superior over usual care. High-intensity SCC tended to be more effective than low intensity SCC but the trend was only statistically significant when combined with NRT.

One strength of our study was the rigorous adherence to systematic review methodology. In addition, our pooled analysis provides a transparent approach to unify evidence from all randomised trials while fully preserving randomisation. Such an analysis may be, in many instances, the only way to estimate comparative effectiveness of all treatments under consideration. Two other approaches for pooling data, often referred to as network meta-analysis, are available [19, 20] but the complexity of their statistical methods may represent a barrier for their application and interpretation [30]. However, one needs to consider that the extent of heterogeneity, also called inconsistency in the context of network meta-analysis, is potentially larger in any network meta-analysis compared to conventional meta-analysis because it is based on a larger number of trials and more interventions. Heterogeneity per se is not a limitation of (network) meta-analysis but results can be misleading if investigators do not deal with heterogeneity appropriately. Quantification and exploration of heterogeneity in (network) meta-analysis is currently an active field of methodological research.

A limitation of our systematic review is that the studies did not provide consistent information about included patients. For example, severity of COPD was not reported consistently by lung function parameters, history of exacerbations or other indicators of disease severity. In addition, the motivation to quit smoking was not described consistently. Thus, we could not assess whether these characteristics influence the effects of smoking cessation interventions, although the statistical methods would allow testing for effect modification.

Although the body of evidence from 7,372 COPD patients included in the network meta-analysis is rather small given the great importance of this intervention for COPD patients, the results are similar to those from the general smoking cessation literature. There is strong evidence that NRT and antidepressants provide significant additional benefit to SCC in COPD patients as is the case for smokers in general $[12,13]$. Although our pooled analysis suggested that high-intensity SCC may enhance prolonged abstinence rates, differences to lowintensity SCC were not significant. Similar results were observed in non-COPD trials [11, 12]. However, there is substantial variation in SCC. In addition, reporting of SCC, which is often individualised to the patients' needs, is challenging. On a meta-epidemiological level, incomplete reporting represents a major barrier to making a clear distinction between high- and low-intensity SCC and may blur differences that exist. A more detailed reporting of SCC would be highly desirable and would offer more insights into the design of effective SCC. 
TABLE 3 Relative efficacies of smoking cessation interventions

\begin{tabular}{|c|c|c|c|}
\hline Counselling alone & $1.82(0.96-3.44), p=0.07$ & & \\
\hline Counselling + NRT & $5.08(4.32-5.97), p<0.001$ & $2.80(1.49-5.26), p=0.001$ & $1.53(0.71-3.30), p=0.28$ \\
\hline
\end{tabular}

Although the results of this pooled analysis seem to be in line with those of the general smoking cessation literature, it is surprising that so little evidence is available for this single, most important treatment for COPD. This contrasts dramatically with the hundreds of trials for other COPD treatments. The general and COPD-specific smoking cessation literature strongly suggests that treatments combining pharmacological and nonpharmacological smoking cessation treatments should be the preferred strategy. However, much more research should be invested to enhance the still dramatically low smoking cessation rates in COPD patients. Barriers for smoking cessation should be explored from the COPD patients' and providers' perspective considering disease severity (defined by pulmonary and extra-pulmonary manifestations), socioeconomic factors and diverse health care settings. This may lead to novel approaches for smoking cessation strategies. More high-quality trials comparing different smoking cessation strategies are needed which are large enough to detect even small differences in prolonged abstinence rates and that have a long follow-up to assess effects on mortality and health care use. The prevalence of COPD is so high that even small gains in effectiveness have a large impact on a population level. Finally, the effects of smoking cessation interventions have never been tested in the context of COPD patient education. Smoking cessation interventions may be considerably more effective if embedded in patient education programmes aimed at improving the patients' self efficacy and health behaviour skills [31].

In conclusion, the pooled analysis showed that combination treatments of SCC with NRT, or presumably less effectively, with an antidepressant are most effective for smoking cessation in COPD patients. However, a much larger research effort is required to further enhance the effectiveness of smoking cessation strategies as the most important single intervention for COPD patients.

\section{STATEMENT OF INTEREST}

A statement of interest for the study can be found at www.erj. ersjournals.com $/ \mathrm{misc} /$ statements.dtl

\section{ACKNOWLEDGEMENTS}

We would like to thank A.K. Kessels (University of Maastricht, Maastricht, the Netherlands) for his statistical analysis advice.

TABLE 4 Relative efficacies of smoking cessation interventions with consideration of intensity of counselling

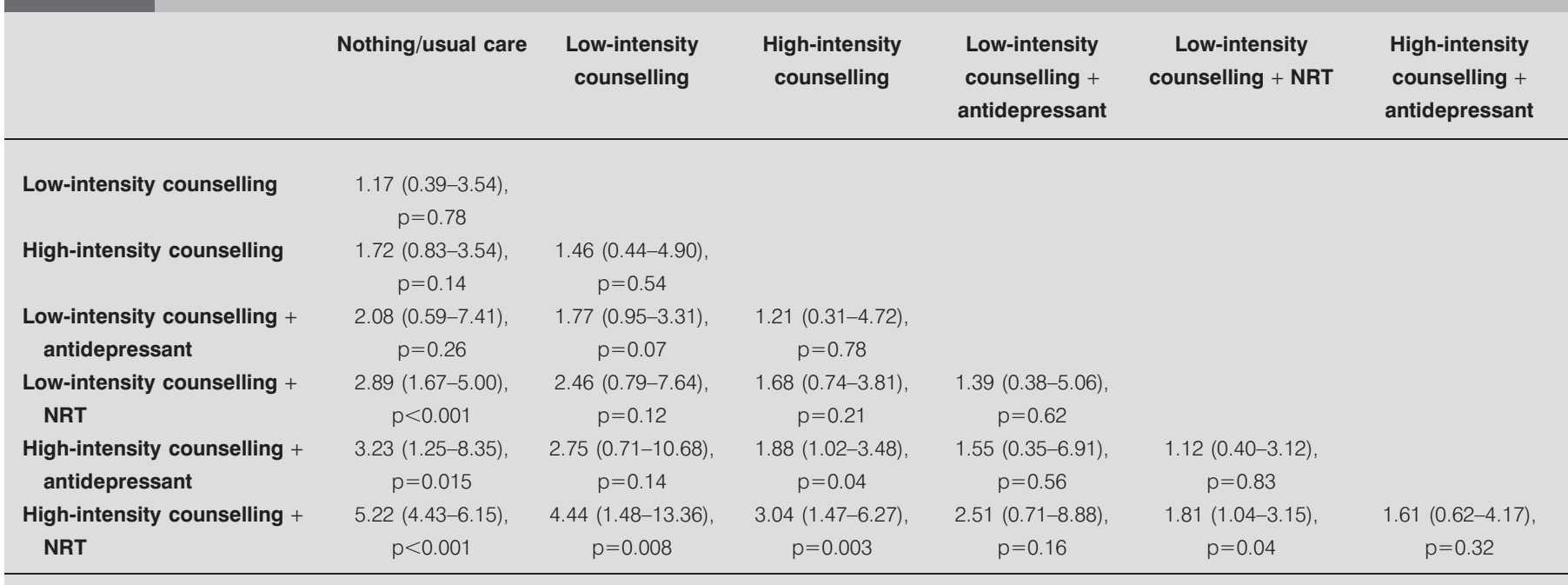

Data are presented as OR $(95 \% \mathrm{Cl})$, p-value; indicating the odds of prolonged abstinence in patients with a smoking cessation intervention from the row as compared to treatment from the corresponding column. NRT: nicotine replacement therapy. 


\section{REFERENCES}

1 American Thoracic Society/European Respiratory Society. Standards for the diagnosis and treatment of patients with chronic obstructive pulmonary disease. 2004. www.ersnet.org/ lrPresentations/copd/files/main/index.html Date last accessed: November 4, 2008.

2 Connett JE, Murray RP, Buist AS, et al. Changes in smoking status affect women more than men: results of the lung health study. Am J Epidemiol 2003; 157: 973-979.

3 Kanner RE, Connett JE, Williams DE, et al. Effects of randomized assignment to a smoking cessation intervention and changes in smoking habits on respiratory symptoms in smokers with early chronic obstructive pulmonary disease: the lung health study. Am J Med 1999; 106: 410-416.

4 Scanlon PD, Connett JE, Waller LA, et al. Smoking cessation and lung function in mild-to-moderate chronic obstructive pulmonary disease. The lung health study. Am J Respir Crit Care Med 2000; 161 : 381-390.

5 Makris D, Moschandreas J, Damianaki A, et al. Exacerbations and lung function decline in COPD: new insights in current and exsmokers. Respir Med 2007; 101: 1305-1312.

6 Anthonisen NR, Skeans MA, Wise RA, et al. The effects of a smoking cessation intervention on 14.5-year mortality: A randomized clinical trial. Ann Intern Med 2005; 142: 233-239.

7 Wagena EJ, van der Meer RM, Ostelo RJ, et al. The efficacy of smoking cessation strategies in people with chronic obstructive pulmonary disease: results from a systematic review. Respir Med 2004; 98: 805-815.

8 Lancaster T, Stead L. Physician advice for smoking cessation. Cochrane Database Syst Rev 2004: 4; CD000165.

9 Lancaster T, Stead LF. Self-help interventions for smoking cessation. Cochrane Database Syst Rev 2005: 3; CD001118.

10 Stead LF, Lancaster T. Group behaviour therapy programmes for smoking cessation. Cochrane Database Syst Rev 2005: 2; CD001007.

11 Lancaster T, Stead LF. Individual behavioural counselling for smoking cessation. Cochrane Database Syst Rev 2005: 2; CD001292.

12 Silagy C, Lancaster T, Stead L, et al. Nicotine replacement therapy for smoking cessation. Cochrane Database Syst Rev 2004; 3: CD000146.

13 Hughes JR, Stead LF, Lancaster T. Antidepressants for smoking cessation. Cochrane Database Syst Rev 2007; 1: CD000031.

14 Jimenez-Ruiz CA, Masa F, Miravitlles M, et al. Smoking characteristics: differences in attitudes and dependence between healthy smokers and smokers with COPD. Chest 2001; 119: 1365-1370.

15 Clark MA, Hogan JW, Kviz FJ, et al. Age and the role of symptomatology in readiness to quit smoking. Addict Behav 1999; 24: $1-16$.
16 Walters N, Coleman T. Comparison of the smoking behaviour and attitudes of smokers who attribute respiratory symptoms to smoking with those who do not. Br J Gen Prac 2002; 52: 132-134.

17 Caldwell DM, Ades AE, Higgins JP. Simultaneous comparison of multiple treatments: combining direct and indirect evidence. $B M J$ 2005; 331: 897-900.

18 Bucher HC, Guyatt GH, Griffith LE, et al. The results of direct and indirect treatment comparisons in meta-analysis of randomized controlled trials. J Clin Epidemiol 1997; 50: 683-691.

$19 \mathrm{Lu} \mathrm{G}$, Ades AE. Combination of direct and indirect evidence in mixed treatment comparisons. Stat Med 2004; 23: 3105-3124.

20 Lumley T. Network meta-analysis for indirect treatment comparisons. Stat Med 2002; 21: 2313-2324.

21 Puhan MA, Bachmann LM, Kleijnen J, et al. Inhaled drugs to reduce exacerbations in patients with chronic obstructive pulmonary disease: a network meta-analysis. BMC Med 2009; 7: 2.

22 Anthonisen NR, Connett JE, Kiley JP, et al. Effects of smoking intervention and the use of an inhaled anticholinergic bronchodilator on the rate of decline of FEV1. The Lung Health Study. JAMA 1994; 272: 1497-1505.

23 Brandt CJ, Ellegaard H, Joensen M, et al. Effect of diagnosis of "smoker's lung". RYLUNG Group. Lancet 1997; 349: 253.

24 Crowley TJ, Macdonald MJ, Walter MI. Behavioral anti-smoking trial in chronic obstructive pulmonary disease patients. Psychopharmacology 1995; 119: 193-204.

25 Hilberink SR, Jacobs JE, Bottema BJ, et al. Smoking cessation in patients with COPD in daily general practice (SMOCC): six months' results. Prev Med 2005; 41: 822-827.

26 Pederson LL, Wanklin JM, Lefcoe NM. The effects of counseling on smoking cessation among patients hospitalized with chronic obstructive pulmonary disease: a randomized clinical trial. Int $J$ Addic 1991; 26: 107-119.

27 Tashkin D, Kanner R, Bailey W, et al. Smoking cessation in patients with chronic obstructive pulmonary disease: a double-blind, placebo-controlled, randomised trial. Lancet 2001; 357: 1571-1575.

28 Tonnesen P, Mikkelsen K, Bremann L. Nurse-conducted smoking cessation in patients with COPD using nicotine sublingual tablets and behavioral support. Chest 2006; 130: 334-342.

29 Wagena EJ, Knipschild PG, Huibers MJH, et al. Efficacy of bupropion and nortriptyline for smoking cessation among people at risk for or with chronic obstructive pulmonary disease. Arch Intern Med 2005; 165: 2286-2292.

30 Pocock SJ. Safety of drug-eluting stents: demystifying network meta-analysis. Lancet 2008; 370: 2099-2100.

31 Bourbeau J, Bartlett SJ. Patient adherence in COPD. Thorax 2008; 63: 831-838. 